\title{
HOW DOES INTERNATIONAL COMPETITIVENESS AFFECT ECONOMIC DEVELOPMENT? A TWO-PHASE HYPOTHESIS
}

\begin{abstract}
Summary
This paper analyses the impact of international competitiveness on economic development, based on the World Economic Forum Global Competitiveness Index (GCI) and GDP/capita of 125 countries during the period 2007-2010. The results reveal two phases of the evolution of competitiveness. When $G C I<4.5$ (on 1-7 scale), any improvement of a country's competitiveness affects current development more than future development. When a country's $G C I$ rises above 4.5 , further improvements of competitiveness will affect future development more than current development. The 4.5 competitiveness threshold is remarkably stable throughout analyzed period.
\end{abstract}

Key words: international competitiveness, development, logistic function

\section{Introduction}

The aim of this paper is examine how international competitiveness affects current and future economic development. Let $x_{t}$ be the index of international competitiveness at time $t$, and $\varepsilon_{t}$ be the GDP/capita elasticity of $x_{t}$. We hypothesize the existence of a threshold $c_{0}$ of $x_{t}$ which discriminates the following impact patterns of international competitiveness on development:

1. When $x_{t}<c_{0}$, then $\varepsilon_{t}>\varepsilon_{t+1}>\varepsilon_{t+2}>\varepsilon_{t+3}>\ldots$;

2. When $x_{t}=c_{0}$ then $\varepsilon_{t}=\varepsilon_{t+1}=\varepsilon_{t+2}=\varepsilon_{t+3}=\ldots$;

3. When $x_{t}>c_{0}$, then $\varepsilon_{t}<\varepsilon_{t+1}<\varepsilon_{t+2}<\varepsilon_{t+3}<\ldots$.

In other words, when a country's competitiveness level is below the threshold $c_{0}$, an improvement of competitiveness will affect current development more than future development. On the other hand, if a country has a level of competitiveness above this threshold, further improvements of competitiveness will affect future economic development more than current development.

Salvatore [2010] follows the commonly accepted definition of international competitiveness as the ability of a country or company to generate more wealth for its people than its competitors in world markets. According to him, international

${ }^{1}$ Dr hab. Hanna G. Adamkiewicz - Faculty of Management and Economics, Gdansk University of Technology, e-mail: had@zie.pg.gda.pl; Prof. dr hab. Stanislaw Maciej Kot - Faculty of Management and Economics, Gdansk University of Technology, e-mail: skot@zie.pg.gda.pl. 
competitiveness is the "growth potential", because it describes the nations' ability and prospects for future growth.

Salvatore's concept of growth potential is the reason for our research. The question is whether international competitiveness affects only the future economic development, or also the current development. Our two-phase hypothesis provides the answer to this question. Countries in the first phase of competitiveness development, i.e. with $x_{t}<c_{0}$, may expect a descending pattern of economic development in current and future years while improving their competitiveness. If countries have achieved the second phase of competitiveness development, i.e. when $x_{t}>c_{0}$, they may expect an ascending pattern of economic development in the current and future years while improving their competitiveness. Finally, if a countries' competitiveness equals the threshold $c_{0}$, any improvement of competitiveness will provide the same economic development in all years.

This paper is organized as follows. Section 2 presents statistical data and the method of modeling the impact of international competitiveness on development. Section 3 shows empirical results. Section 4 provides conclusions and suggests the directions of further research.

\section{Data and methods}

\subsection{Statistical data}

We measure economic development by GDP/capita. The GDP/capita data are for the years 2007-2010 come from WDI (2010) and given in international US dollars (2005 constant prices). We measure international competitiveness according to the World Economic Forum Global Competitiveness Index (GCI). GCI, ranging from 1 to 7, is a weighted average of several different components, each measuring a different aspect of competitiveness [Schwab, Porter, 2008]. In this paper, we use GCI data for 125 countries in the years 2007-2009.

Luxemburg and Qatar seem to be outliers when analyzing GDP/capita. Table 1. includes the Grubbs [1969] test for the initial sample and a sample without these two outliers.

TABLE 1.

The Grubbs test for outliers in GDP/capita, all cases

\begin{tabular}{|c|c|c|c|c|}
\hline \multirow{2}{*}{ Variable } & \multicolumn{2}{|c|}{ Initial sample } & \multicolumn{2}{c|}{ The sample without LUX \&QAT } \\
\cline { 2 - 5 } & Statistic & p-value & Statistic & p-value \\
\hline GDP 2007 & 3.81485 & 0.01047 & 2.62185 & 0.95880 \\
GDP 2008 & 4.10349 & 0.00260 & 2.64767 & 0.87676 \\
GDP 2009 & 4.09105 & 0.00273 & 2.73085 & 0.66719 \\
GDP 2010 & 4.31720 & 0.00072 & 3.19973 & 0.11744 \\
\hline
\end{tabular}

Source: Own calculations using [WDI, 2010] data. 
Table 1. shows that the sample becomes homogeneous when Luxemburg and Qatar are excluded.

Table 2. presents basic descriptive statistics of selected variables in the sample without the outliers.

TABLE 2.

Descriptive statistics of Global Competitiveness Index (GCI) and GDP/capita (data without outliers: Luxembourg and Qatar)

\begin{tabular}{|l|r|r|r|r|r|}
\hline \multicolumn{1}{|c|}{ Variable } & \multicolumn{1}{|c|}{ Valid N } & \multicolumn{1}{c|}{ Mean } & \multicolumn{1}{c|}{ Minimum } & \multicolumn{1}{c|}{ Maximum } & \multicolumn{1}{c|}{ Std. Dev. } \\
\hline GCI 2007 & 124 & 4.19 & 2.50 & 5.81 & 0.80 \\
GCI 2008 & 123 & 4.18 & 2.85 & 5.74 & 0.67 \\
GCI 2009 & 131 & 4.16 & 2.58 & 5.60 & 0.66 \\
GDP 2007 & 121 & 14196.88 & 354.65 & 49876.95 & 13608.74 \\
GDP 2008 & 120 & 14001.57 & 359.61 & 48557.30 & 13051.39 \\
GDP 2009 & 119 & 13351.27 & 361.84 & 47264.07 & 12418.39 \\
GDP 2010 & 110 & 12682.49 & 366.44 & 51969.47 & 12278.22 \\
\hline
\end{tabular}

Source: Own calculations using data from: [Schwab, Porter, 2008; WDI, 2010].

\subsection{The method}

Our aim is to detect the exclusive effect of international competitiveness on development. Therefore we build econometric models with GDP/capita as dependent variable $y$, and $G C I$ as the single independent variable $x$. Initial analysis of statistical data shows that the relationship between GDP/capita and GCI is nonlinear. The following logistic function seems to fit the data the best in the light of $\mathrm{R}^{2}$ criterion:

$$
y=\frac{a}{1+\exp \{-(b+c x)\}}, \mathrm{a}, \mathrm{c}>0,
$$

where $a, b$, and $c$ are the parameters.

Logistic function (1) is the solution to the following differential equation:

$$
\frac{d y}{d x}=\frac{c}{a} y(a-y) .
$$

Eq. (2) shows that the reaction of development to an increase of competitiveness is proportional to the already achieved level $y$ and to the distance $a-y$ from the saturation level $a$.

The GDP/capita elasticity $\varepsilon$ of international competitiveness is the following function of $x$ :

$$
\varepsilon(x)=\frac{c x}{1+\exp \{b+c \cdot x\}} .
$$

We estimate the parameters of nine logistic models using the STATISTICA package non-linear least squares method. Each of these models describes the impact of $G C I$ in the year $t$ on GDP/capita in the year $t+k$, where $k=0,1,2,3, t=2007,2008$ and 2009. Thus 
we estimate four models for $t=2007$, three models for $t=2008$, and two models for $t=2009$ - because WDI(2010) offers GDP/capita data up to 2010.

\section{Results}

Table 3. summarizes the estimation results of four logistic models (1) with GDP/capita as a dependent variable for the years $2007,2008,2009$, and 2010 , where the $G C_{2007}$ is a single independent variable of each of these four models.

TABLE 3.

The estimated logistic models (1) of GDP/capita against GCI 2007 (standard errors in parentheses)

\begin{tabular}{|c|c|c|c|c|c|}
\hline Model No. & GDP/capita & a & $\mathbf{b}$ & $\mathrm{c}$ & $\begin{array}{c}\text { Proportion of } \\
\text { variance } \\
\text { accounted for }\left(R^{2}\right)\end{array}$ \\
\hline 1 & 2007 & $\begin{array}{l}39991.53708 \\
(3614.45950)\end{array}$ & $\begin{array}{l}-9.83312 \\
(1.38602)\end{array}$ & $\begin{array}{c}2.14977 \\
(0.35035)\end{array}$ & 0.76769 \\
\hline 2 & 2008 & $\begin{array}{l}41742.06318 \\
(3943.17191)\end{array}$ & $\begin{array}{l}-9.20974 \\
(1.10663)\end{array}$ & $\begin{array}{c}1.97624 \\
(0.28582)\end{array}$ & 0.81569 \\
\hline 3 & 2009 & $\begin{array}{l}40782.72888 \\
(4190.37683)\end{array}$ & $\begin{array}{l}-8.93714 \\
(1.05714)\end{array}$ & $\begin{array}{c}1.90074 \\
(0.27644)\end{array}$ & 0.81802 \\
\hline 4 & 2010 & $\begin{array}{l}47551.55456 \\
(7156.03567)\end{array}$ & $\begin{array}{l}-8.28560 \\
(0.89150)\end{array}$ & $\begin{array}{c}1.67540 \\
(0.24864)\end{array}$ & 0.84363 \\
\hline
\end{tabular}

Source: Own calculations using data from [The Global Competitiveness Report..., 2007-2008; WDI, 2010].

Similarly, Table 4. presents the estimation results of three logistic models (1) with $G D P /$ capita as a dependent variable for the years 2008, 2009, and 2010, with $G_{2} I_{2008}$ as the single independent variable of each of these three models.

TABLE 4.

The estimated logistic models (1) of GDP/capita against GCI 2008 (standard errors in parentheses)

\begin{tabular}{|c|c|c|c|c|c|}
\hline $\begin{array}{c}\text { Model } \\
\text { No. }\end{array}$ & GDP/capita & a & b & c & $\begin{array}{c}\text { Proportion of } \\
\text { variance } \\
\text { accounted for }\left(\mathbf{R}^{2}\right)\end{array}$ \\
\hline 5 & 2008 & 42246.494791 & -10.381609 & 2.258279 & 0.76483 \\
& & $(4081.695)$ & $(1.318)$ & $(0.335)$ & \\
6 & 2009 & 41013.104058 & -10.096100 & 2.185260 & 0.76454 \\
& & $(4221.165)$ & $(1.281)$ & $(0.328)$ & \\
7 & 2010 & 49760.433369 & -9.018812 & 1.838223 & 0.81507 \\
& & $(7727.094)$ & $(0.967)$ & $(0.266)$ & \\
\hline
\end{tabular}

Source: Own calculations using data from [The Global Competitiveness Report..., 2008-2009; WDI, 2010]. 
Finally, Table 5. shows the estimation results of two logistic models (1) with GDP/ capita as a dependent variable for the years 2009 and 2010 and GCI $_{2009}$ as the single independent variable of each of these two models.

TABLE 5.

The estimated logistic models (1) of GDP/capita against GCI 2009 (standard errors in parentheses)

\begin{tabular}{|c|c|c|c|c|c|}
\hline $\begin{array}{c}\text { Model } \\
\text { No. }\end{array}$ & GDP/capita & a & b & c & $\begin{array}{c}\text { Proportion of } \\
\text { variance } \\
\text { accounted for }\left(\mathbf{R}^{2}\right)\end{array}$ \\
\hline 8 & 2009 & 41496.83483 & -10.33433 & 2.25141 & 0.77801 \\
& & $(4148.65130)$ & $(1.25382)$ & $(0.32261)$ & \\
9 & 2010 & 49272.55165 & -9.20171 & 1.90328 & 0.81115 \\
& & $(7322.10303)$ & $(1.00668)$ & $(0.27579)$ & \\
\hline
\end{tabular}

Source: Own calculations using data from [The Global Competitiveness Report..., 2009-2010; WDI, 2010].

Tables 3.-5. show that all the parameters are statistically significant (at a 0.05 level of significance). The goodness of fit of the logistic function is surprisingly high bearing in mind that GDP/capita is explained by a single variable only. This means that the Global Competitiveness Index seems to cover most of the factors which influence economic development.

We have also experimented with other functions, e.g. linear, exponential, polynomials, etc. while approximating the relationship between GDP/capita and GCI. However, none of these functions fits the data better than logistic function (1). We have discarded linear functions also because they predict negative GDP for low levels of GCI.

Figure 1. shows the elasticity functions (3) of the logistic models presented in Table 3.

Figure 1. shows that all elasticity functions are positive. This means that an improvement of international competitiveness enhances economic development and that elasticity functions intersect approximately at competitiveness level 4.5. When $G C I<4.5$, the improvement of a county's competitiveness affects current development more than future development. On the other hand, the improvement of a country's competitiveness affects future development more than current development when $G C I>4.5$.

In Figure 2. and Figure 3. one can observe exactly the same pattern of the impact of international competitiveness on development. It is remarkable that in all the above figures elasticity functions intersect almost at the same point, 4.5. This confirms our two-phase hypothesis. 
FIGURE 1.

$G D P /$ capita elasticity of international competitiveness 2007

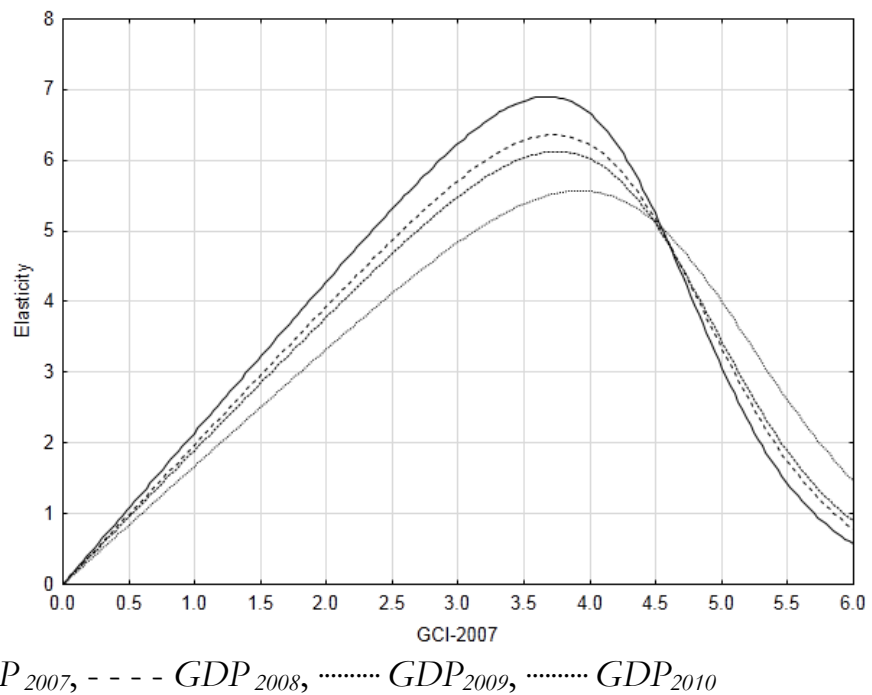

Source: Own calculations using data from Table3-5.

FIGURE 2.

$G D P /$ capita elasticity of international competitiveness 2008

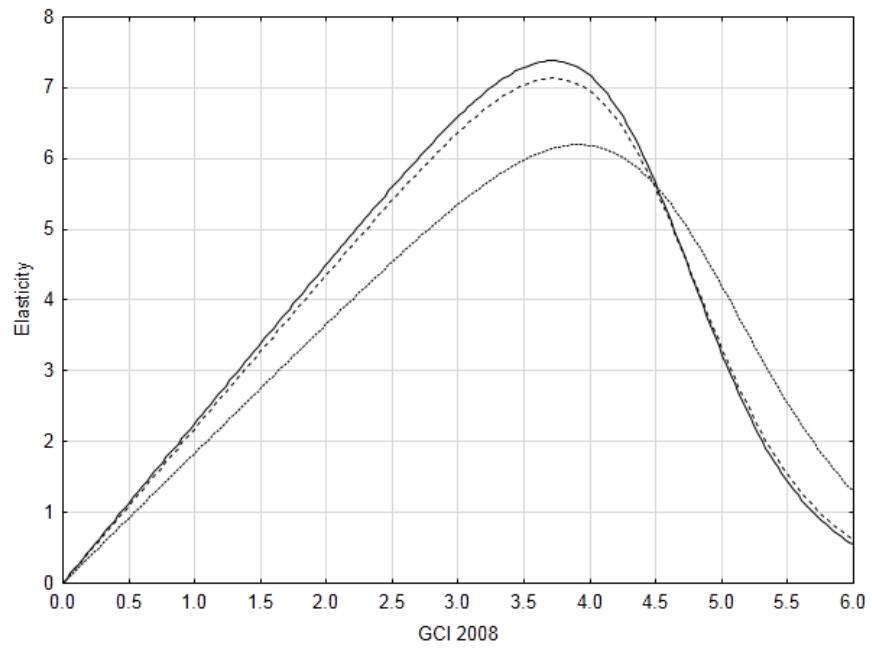

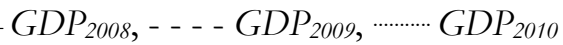

Source: Own calculations using data from Tables 3-5. 
FIGURE 3.

\section{GDP/capita elasticity of international competitiveness 2009}

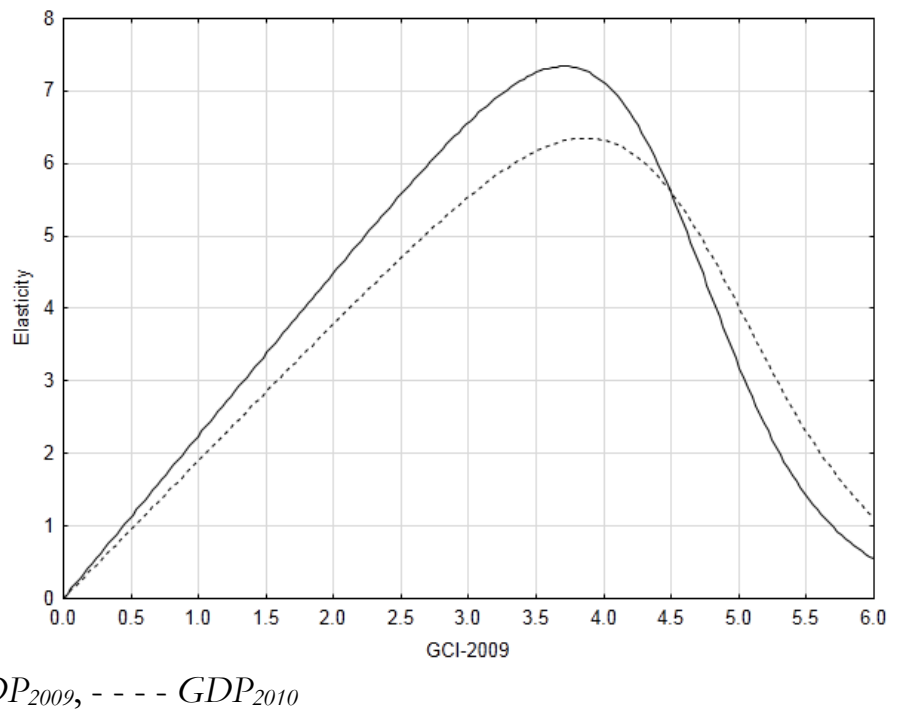

Source: Own calculations using data from Tables 3-5.

\section{Conclusions}

Three general conclusions may be drawn from our research. First, international competitiveness enhances economic development. The logistic form of the relationship between GDP/capita and GCI, among other things, means that the impact of competitiveness on development varies according to a country's level of competitiveness.

Second, there is an optimal level of international competitiveness $(3.5,4.0)$ that provides a maximal GDP/capita elasticity.

Third, countries with low competitiveness may enjoy immediate effects of economic development while improving their competitiveness. On the other hand, when highly competitive countries invest in further improvement of their competitiveness they may expect a greater economic development in the future rather than the present.

Obviously, alternative approaches are possible when modeling the impact of international competitiveness on development. For example, GDP/capita may be regressed on present and past GCI values. Dynamic panel data models can be used for this purpose. Also individual pillars of competitiveness can be used instead of the GCI in such models. These are the approaches we plan to adopt in further research.

\section{Bibliography}

Grubbs. F. 1969 Procedures for Detecting Outbing Observations in Samples, „Technometrics”, No. 11. 
Porter M.E., Schwab K. 2008 The Global Competitiveness Report 2008-2009, Geneva.

Porter M.E., Schwab K., Sala-i-Martin X. 2007 The Global Competitiveness Report 2007-2008, Geneva.

Salvatore D. 2010 Globalization, International Competitiveness and Growth: Advanced and Emerging Markets, Large and Small Countries, ,Journal of International Commerce, Economics and Policy", No. 1.

Schwab K., Sala-i-Martin X. 2009 The Global Competitiveness Report 2009-2010, Geneva.

WDI World Development Indicators 2010, Washington DC. 